\title{
O Brazilian-American Cultural Institute como ferramenta político-cultural (1964-2007)
} DÁRIA JAREMTCHUK ${ }^{I}$

\section{Introdução}

1 COMPANHAR a história do Brazilian-American Cultural Institute (Baci) possibilita conhecer aspectos da diplomacia cultural brasileira nos Estados Unidos durante o período da guerra fria. Como aqui se verá, a instituição não se restringiu à promoção da cultura e da língua brasileiras no exterior, pois a sua configuração jurídica inicial e a presença de congressistas estadunidenses em seu conselho sugerem conexões entre a sua criação e estratégias utilizadas pelos Estados Unidos para aumentar o seu campo de influência na América Latina após a Revolução Cubana.

Desse modo, a primeira parte deste artigo apresenta os fatos que levaram à criação do Baci, bem como a sua configuração diferenciada de outros institutos de língua e de cultura mantidos pelo Itamaraty no exterior. Já década de 1970, a instituição passou por uma fase mais profissional, consequência de interesses do regime militar brasileiro, que pretendeu promover uma imagem de benfeitor das artes e da cultura como contraponto aos relatos dos exilados políticos que denunciavam no exterior a censura, a repressão e a tortura praticadas no Brasil. Por fim, a reflexão apresenta os últimos anos do Baci e a sua extinção em 2007.

A hipótese aqui apresentada é a de que os espaços de arte e de cultura funcionaram como importantes ambientes de articulação social nas atividades diplomáticas e comerciais, sendo o Baci um caso bastante revelador desse processo. No entanto, essa realidade se altera no mundo contemporâneo globalizado, pois os espaços artísticos e culturais parecem ter deixado de ser vitais para a prática da diplomacia cultural contemporânea, como o fechamento do Baci revela.

\section{A criação do Baci e ações da diplomacia cultural brasileira nos Estados Unidos}

Criado oficialmente em 1964, o Brazilian-American Cultural Institute (Baci) já funcionava na Embaixada brasileira em Washington, D.C., desde 1961, como um embrião de centro binacional baseado nos modelos lançados pelo Itamaraty em Montevidéu, Assunção, Buenos Aires e La Paz. A decisão de formalizar a unidade nos Estados Unidos foi do então embaixador Roberto 
de Oliveira Campos, quando solicitou ao Ministério das Relações Exteriores os estatutos das unidades na América Latina para que lhe servissem de base. ${ }^{2}$ Apesar da similaridade entre os institutos, a sede em Washington, D.C., seguiria trajetória distinta, tornando-se uma organização não lucrativa regida pelas leis daquele país. À vista disso, o formato não teria partido de diretrizes elaboradas pelo Ministério das Relações Exteriores (MRE), mas de uma demanda específica da Embaixada. Nesse sentido, Cícero Martins Garcia explica os movimentos desse órgão governamental:

Os CEBs [Centros de estudos Brasileiros] e Institutos Culturais brasileiros, ao contrário dos institutos de idiomas de vários outros países, não tiveram sua criação determinada por nenhuma decisão central tomada pelo Governo, mas foram surgindo de forma empírica em países nos quais o Brasil mantinha Missões diplomáticas ou Repartições consulares, em virtude de iniciativas individuais ou de acordos culturais bilaterais firmados entre o Brasil e o país-sede. É curioso registrar a distribuição temporal do momento de criação dos CEBs ou Institutos, pois a mesma demonstra não haver concentração em nenhuma época específica, que pudesse indicar alguma iniciativa de política cultural tomada por determinada administração do Itamaraty. (Garcia, 2003, p.111-2)

Se, por um lado, a sede em Washington, D.C., parece se encaixar nessa perspectiva, por outro, apresenta peculiaridades relacionadas ao contexto da guerra fria na América Latina. Analisando os movimentos de sua criação e seus primeiros anos de existência, é possível localizar uma aproximação de parte de setores do governo dos Estados Unidos em direção ao Baci. Tal afirmação apoia-se na análise dos documentos produzidos pela própria instituição, nos quais estão presentes nomes de congressistas estadunidenses em seu Board of Directors. Tal participação não parece se encaixar na chave da filantropia e tampouco da casualidade.

Como o surgimento do Baci ocorreu antes do golpe civil-militar, quando ainda predominava no Brasil a Política Externa Independente, ${ }^{3}$ percebe-se que o movimento dos Estados Unidos em apoiar a criação do Instituto estaria ligado a outro jogo de interesses. Já em 1963, o presidente John Kennedy felicitou o lançamento do Baci, antes mesmo de sua oficialização, que aconteceu somente em 1964:

O povo dos Estados Unidos tem muito a aprender com o rico patrimônio histórico e cultural do Brasil; estou feliz em constatar a criação de novo Brazilian - United States Institute aqui em Washington para facilitar maiores contatos culturais e educacionais entre nossos dois países. ${ }^{4}$

A declaração pode indicar que estava em curso um acompanhamento do governo daquele país sobre assuntos ligados à diplomacia brasileira, o que leva a crer que a formalização jurídica do Baci estivesse nesse entremeio. Por esse contexto de análise, a história do Baci deixa de ser um estudo de caso isolado e passa a revelar conexões com a nova geopolítica das Américas uma vez que se 
tornou um espaço voltado para o exercício da diplomacia cultural e aproximação da elite intelectual e econômica estadunidense interessada no Brasil.

Assim, o caso do Baci é bastante ilustrativo desse processo e possibilita reconhecer alinhamentos de condutas entre setores do governo dos Estados Unidos e instituições que em nada parecem aleatórios, o que leva a pressupor algum tipo de envolvimento entre governo, empresas comerciais e fundações privadas. Afinal, seu surgimento como entidade cultural sem fins lucrativos (non profit organization), independente da Embaixada, sujeita às leis dos Estados Unidos e gerida por um conselho misto, não correspondia às práticas do Itamaraty mais frequentes em outros postos diplomáticos, com exceção do Instituto Cultural Uruguaio-Brasileiro (Icub) de Montevidéu, outra entidade de direito privado local (Garcia, 2003, p.117). Pode-se inferir que as Missões Culturais pareciam cumprir as metas de difundir a língua portuguesa e a cultura brasileira e não há indícios de que em Washington, D.C. devesse ser diferente, como se pode ler nesse documento da Embaixada:

O Baci foi criado e incorporado em Washington, D.C., como uma organização sem fins lucrativos, em 22 de fevereiro de 1964, pelo Itamaraty e por um grupo de parlamentares e profissionais liberais norte-americanos, como o propósito de estabelecer intercâmbio cultural, pedagógico e artístico entre o Brasil e os Estados Unidos. ${ }^{5}$

Sem entrar na questão sobre a excepcionalidade do ordenamento da organização, de todo modo pode-se afirmar que foi a partir da criação dessa sociedade jurídica que se franqueou a participação deliberativa tanto de congressistas como de cidadãos estadunidenses na agenda do Baci. Portanto, se o Ministério das Relações Exteriores do Brasil foi o seu maior mantenedor financeiro, seguramente, ao menos em seus primeiros anos, não foi seu único mentor intelectual. ${ }^{6}$ A presença de congressistas, como Bradford Morse, Donald Irwin e John Brademas, foi constante e bastante ativa na década de 1960.7 Talvez seja aqui necessário lembrar que o Congresso dos Estados Unidos foi peça-chave na execução de políticas para a América Latina.

Apesar de juridicamente independente e com diretrizes traçadas por seu conselho, o Baci foi gerido até 1970 por diplomatas brasileiros que se dividiam entre os assuntos culturais da Embaixada e as atividades do Instituto. ${ }^{8} \mathrm{~A}$ ideia sempre fora de que o espaço se tornasse autônomo financeiramente. No entanto, como entidade binacional, desde seus primórdios e para efetivar o empreendimento, a Embaixada sustentou financeiramente o projeto, pagando os gastos com a manutenção e os salários dos professores e funcionários, por exemplo. Acreditava-se que empresas privadas estadunidenses interessadas no Brasil e empresas brasileiras interessadas nos Estados Unidos iriam apoiar o projeto e assumir os custos da instituição, possibilitando autonomia em relação à Embaixada, mesmo que isso não significasse a retirada do apoio oficial do Itamaraty e da permanência de seu status simbólico de representação. As doações, que parecem 
ter sido formas indiretas de explicitar os interesses comerciais dos doadores, estiveram na pauta do Baci desde o seu início. A lista de empresas estadunidenses com interesses no Brasil não era pequena, figurando não apenas a Standart Oil Co., como o Chase Manhattan Bank, sendo inclusive o seu diretor, David Rockfeller, um dos membros do Board of Advisors do Baci.

O exemplo mais expressivo dessa cooperação foi o de Harold E. Wibberley Jr., que em 1966 se interessou em custear a instalação da Biblioteca do Instituto. Wibberley era o presidente da Baker-Wibberley \& Associates (Consulting Engineers), que havia ganhado uma concorrência para traçar os planos da estrada entre Rio de Janeiro e Lima. No entanto, essas parcerias não se tornaram constantes e foram buscadas em circunstâncias específicas, como nos momentos em que a crise financeira se exacerbava, ou então quando o governo brasileiro passou a apresentar perfil político mais liberal, como o da década de $1990 .{ }^{9}$

A função institucional do Baci, apesar de seu caráter híbrido de parcerias privadas, implica, portanto, uma via dupla. Se, por um lado, compreende-se melhor a institucionalização do espaço quando observada sob a ótica dos interesses dos Estados Unidos em se aproximar da América Latina após a Revolução Cubana, por outro, não se pode esquecer que também houve, por parte do regime militar, objetivos concretos em relação àquele país, para os quais o uso das artes foi bastante conveniente.

Segundo o diplomata Fernando de Mello Barreto (2014, p.8-9), "nos três primeiros anos do regime militar, isto é, durante o governo do General Castelo Branco (entre abril de 1964 e março de 1967), houve política externa autoqualificada de "fidelidade ao Ocidente'". Isso significava um alinhamento aos Estados Unidos e uma concordância com suas políticas contrárias aos regimes comunistas, perfeitamente condizentes com o clima da guerra fria. No entanto, diferente da gestão castelista, durante o governo do marechal Arthur da Costa e Silva (15 de março de 1967 a 31 de outubro de 1969), houve uma mudança na política externa e marcas mais nacionalistas se sobressaem, notadamente em relação ao regime castelista anterior. Já no governo Médici (de 31 de outubro de 1969 a 15 de março de 1974), que coincidiu com o de Nixon, "as relações com os Estados Unidos voltariam a ser mais fluidas" (ibidem, p.8-15). No entanto, mesmo que não houvesse durante todo o período da ditadura brasileira uma política externa linear em relação aos Estados Unidos, o regime militar necessitava do apoio daquele país.

O Itamaraty costumava apresentar arte e cultura brasileiras em diversos postos diplomáticos. Nesse sentido, embora não seja possível desenhar um quadro comparativo e delinear com precisão as diferenças entre as ações diplomáticas anteriores ao golpe, observa-se na documentação aqui pesquisada que, durante o governo militar, houve um interesse direto em transformar os eventos artístico-culturais em espécies de cartões de visitas do Brasil. Por exemplo, para que artistas conseguissem auxílio para subsidiar a realização de mostras no 
estrangeiro, solicitava-se com frequência ao Sistema Nacional de Informações (SNI) dados sobre eles. Consequentemente, qualquer posicionamento político ou manifestação contrária ao regime militar comprometia a obtenção desses subsídios institucionais. São conhecidos alguns casos desse controle. A título de exemplo, a Divisão de Difusão Cultural do Itamaraty enviou em 1969 ao presidente da República, marechal Arthur da Costa e Silva, uma lista com nomes de artistas que teriam obras exibidas no exterior. O SNI esclareceu que, sobre a grande maioria deles, nada constava que os "desabonasse". No entanto, advertiu que alguns haviam contestado o regime e tinham ligações com a esquerda, como o pintor João Câmara, que mantinha "atividades comunistas e suspeitas". Câmara havia exposto, quando em Recife, na Galeria de Arte da Faculdade de Direito, e de lá seus trabalhos foram retirados por serem considerados "como ofensivos aos costumes, à religião e à Revolução". ${ }^{10}$ No caso de Elza de Souza, mesmo "não havendo nada contra ela", ressaltou-se ter viajado para os países da Cortina de Ferro (Polônia e Checoslováquia). Já sobre as artistas Marília Rodrigues e Maria Bonomi, respectivamente, os históricos são mais detalhados. Sobre a primeira artista, constava:

Simpatizante comunista. Esquerda ativa. Assinou manifesto de agitação pró Universidade de Brasília, Hélio Fernandes e Oscar Niemeyer. Assistente do Instituto Central de Artes da UnB. Figurante de uma relação de professores demissionários da UnB, em 18 out. 67, em solidariedade a outros professores demitidos pela Reitoria. ${ }^{11}$

Sobre Bonomi, registrava-se:

Xilógrafa. Pintora. Assinou manifesto pela liberdade de Ênio Silveira. Assinou manifesto, em São Paulo, condenando a nova Constituição. Assinou manifesto de repúdio à Lei de Imprensa. Incluiu seu nome em um abaixo-assinado conclamando o povo a unir-se contra o governo que coagia o Congresso. Esquerda atuante. ${ }^{12}$

Por sua vez, Regina Vater, que era filha de militar, foi considerada "marginada figura", pela participação em protestos contra a censura. No ano 1972, a Divisão de Segurança e Informação do Ministério das Relações Exteriores solicitou ao SNI dados sobre seus antecedentes, pois o Departamento Cultural do Ministério estudava a possibilidade de patrocinar suas mostras, que circulariam em 1973 por Colômbia, Peru, Venezuela e México. Dessa vez, o ofício do SNI, acompanhado de recortes de jornais, informava que em 1968 ela havia portado cartazes contra a ditadura na passeata dos 100 mil e que no ano seguinte esteve presente em manifestações de rua com comícios relâmpagos e discursos inflamados. ${ }^{13} \mathrm{O}$ deferimento da solicitação por parte do Ministério parece ter sido negativo, pois a artista não realizou mostras nesses países. Ou então, por algum outro motivo, as exposições não se realizaram.

A prática de controle e monitoramento das mostras em espaços diplomáticos parece ter sido frequente. A Embaixada de Roma, por exemplo, solicitou, 
em julho de 1977, à Divisão de Segurança e Informações do MRE, os endereços de artistas que iriam expor. Pretendia perguntar a eles não só sobre o interesse em expor em Roma, mas também "na eventualidade dos nominados possuírem antecedentes nesse OI a DSI/MRE agradeceria ser informada". A lista não era extensa, dela constavam Gerson de Souza, Manabu Mabe, Wanda Pimentel, Aldemir Martins, Genaro, Anísio Medeiros, Rubem Valentim, Clóvis Graciano, Gilvan Samico, Moacir de Andrade, Alfredo Volpi e Milton Dacosta. As esparsas informações apresentadas levam a supor que o controle era realizado a partir da filiação e dos contatos com o Partido Comunista, assim como pelo fluxo de viagens e de correspondência recebida dos países comunistas, e não por meio de um monitoramento sistemático da classe artística em geral. Os exemplos descritos no documento elaborado pelo Divisão de Segurança e Informações revelam a importância dessas conexões:

Gerson de Souza - nada temos registrado; Gerson de Souza Nunes - eleitor inscrito no PCB, na 20 a Zona Eleitoral, do Município de Magé/RJ; Manabu Mabe - Vide Documento de Informações 1811/60/AC/73, de 18 set 73, difundido na época para essa DSI; Aldemir Martins - nada temos registrado; Genaro - apenas este nome, falta-nos elementos para informar; Clovis Graciano - pintor, filiado em 1976 ao Instituto Cultural Brasil/ URSS; Moacir de Andrade - elemento de esquerda atuando no Departamento de Esportes do Jornal do Brasil; Milton Dacosta - em 1965 recebeu correspondência oriunda da URSS. ${ }^{14}$

Apesar dos indícios de acompanhamento de ações, de correspondências e de centralização por parte das agências de informação e ministérios, há indícios que demonstram certo protagonismo dos diplomatas responsáveis por postos consulares, que divergiram desse modus operandi do Ministério das Relações Exteriores. Esse parece ter sido o caso do Consulado Geral do Brasil em Nova York, com o diplomata Lauro Soutello Alves. Na cidade, havia uma pequena sala de exposições bastante ativa com mostras regulares, que parece ter recebido atenção especial no que se refere à indicação de agendas:

Encareço a necessidade de as mostras serem divulgadas pela imprensa com antecedência, bem como, na medida do possível, o contato com críticos de arte locais. A importância das manifestações culturais na cidade, sobretudo quando os artistas interessados estiverem presentes, como é o caso de Erika Steinberg e Antonio Maia, devem merecer da Vossa Senhoria todo o apoio para que os expositores consigam penetrar no meio artístico. ${ }^{15}$

O cônsul Lauro Soutello Alves, por exemplo, sugeriu modificações na agenda recebida e as enviou para a aprovação de Brasília. O calendário alterava datas de mostras de artistas como Emilio Castellar, Sonia Ebling, Carlos Scliar, entre outros. ${ }^{16}$ Já as mostras de Nicola e de Anna Letycia, programadas para outubro e novembro de 1969 , seriam canceladas por contingenciamento de despesas. ${ }^{17}$ Ainda em relação ao ano de 1969 , Soutello Alves sugeriu a realização 
da mostra de Antonio Dias na galeria de Nova York, em substituição à coletiva de Jean Boghici que, devido ao atraso, comprometia o calendário previsto. $\mathrm{O}$ diplomata afirmava que Dias viajaria de Milão, onde morava, para os Estados Unidos por conta própria e que suas obras sairiam do Rio e se encontravam prontas, aguardando apenas a autorização para a viagem. Uma lista com os títulos dos trabalhos acompanhava a correspondência enviada à Secretaria de Relações Exteriores. ${ }^{18}$ No texto, o diplomata salientava que Dias era um "artista jovem e já de renome internacional com ótima crítica no Brasil e na Europa". ${ }^{19}$ Chama a atenção nesse contexto não apenas a gerência direta do diplomata na agenda do espaço cultural, mas também a seleção de obras, cujos temas eram diretamente relacionados à violência explícita, às imagens de corpos, de vísceras em cores vermelhas e esqueletos, aspectos evidenciados na resenha da mostra publicada na revista Arts Magazine:

Violence is the keynote - and all the images are convulsively subverted to it. Skulls grimace in a sustained shriek, blood is in grimly dripping abundance, human organs are wrenched into sinister fragments - it is a world in festering disarray. [...] Basically, Dias confines himself to reds, yellows, and blacks which are garishly expressive on one level, and visually slick on another. The language of Pop and advertising art there, but rather than trapping their manipulator in his methods, they serve as gruesomely effective vehicles for his message. ${ }^{20}$

O mesmo conjunto de trabalhos teria dificuldades em ser exibido no Brasil naqueles anos finais de 1960. Nesse caso, percebe-se um descompasso entre o que era tolerado no exterior e no Brasil, no que diz respeito às artes. Soutello Alves enfatizou, na sua correspondência com Brasília, que a escolha do artista se justificava por sua projeção internacional, fato que poderia minimizar associações entre suas obras e eventuais críticas ao regime militar. A permissividade talvez estivesse apoiada na orientação do Ministério das Relações Exteriores em querer projetar positivamente o Brasil no estrangeiro, ou então na escolha pessoal do diplomata, que queria organizar a agenda de mostras do Consulado em Nova York, sem se importar com a censura e as proibições que ocorriam no Brasil. Mesmo que não se possa afirmar categoricamente, pode-se aqui assumir a hipótese de que, crítico à ditadura e vivendo na Europa, o "artista brasileiro" Antônio Dias poderia ser útil, por levar junto às notícias de sua exibição pelos Estados Unidos, o "nome do Brasil". Afinal, suas obras, com as de Roberto Magalhães, já haviam sido "testadas" dois anos antes na Galeria Debret, espaço "chapa branca" do Consulado brasileiro em Paris. O termo flexibilidade, ou mesmo acomodação de vertentes contrárias sob um mesmo viés, parece ser o mais adequado para se pensar esse trânsito de mostras nos postos diplomáticos. Ou seja, o Itamaraty, ao que tudo indica, não foi pressionado a seguir a mesma agenda restritiva e de censura às artes que ocorria no Brasil.

Outro exemplo notável, no que se refere às mostras sob a tutela territorial do Consulado em Nova York, foi uma ação de resistência à ditadura de 
alguma forma relacionada às mostras oficiais brasileiras na cidade. Os artistas do Movimiento por la Independencia Cultural de Latino América (Micla) fizeram denúncia das práticas de violência do regime militar na abertura da exposição de ex-votos brasileiros dos séculos XVIII e XIX, que teria ocorrido na Galeria Bonino, ${ }^{21} \mathrm{em}$ Nova York. É de Luis Camnitzer o relato sobre a abertura da mostra, na qual os integrantes do Micla, em conjunto com o Committee for Justice for Latin American Prisoners, estiveram presentes: "enquanto os membros do Comitê distribuíam panfletos aos visitantes, os artistas do Micla davam pequenas bonecas 'contra ex-votos' com bandagens marcadas em vermelho". ${ }^{22}$ Como a mostra recebia o apoio oficial brasileiro, a ação acabou causando mal-estar, pois as bandagens das bonecas pintadas de vermelho que eram entregues aos visitantes vinham acompanhadas de relatos de vítimas de tortura. Pode-se aqui talvez supor que a mostra de ex-votos fosse na realidade uma exposição pertencente a Jean Boghici, provavelmente exibida em outubro de 1969, sob os auspícios do Consulado de Nova York. ${ }^{23}$

Embora não tenha sido possível localizar diretrizes do Ministério da Relações Exteriores para o Baci em seus primeiros anos de existência, essa realidade se alterou na década seguinte, quando a instituição passou a ser utilizada pelo regime militar para apresentar uma faceta menos repressora do país em relação às artes.

\section{O Baci nos anos de 1970 e a ditadura militar}

Indícios apontam ter sido apenas no final da década de 1960 que o Itamaraty acompanhou mais diretamente a programação do Baci. Essa constatação conecta-se com a atenção que o regime militar passou a dar à veiculação de sua imagem no exterior. Uma notícia sobre a abertura de exposição em 1967 indica a necessidade de propagar o "clima de normalidade política" no país, apesar da ditadura vivida:

Mr Hasslocher informed the Board that on January 27 at 6:00 p. m. there will be a reception for the opening of an art exhibit of Brazilian Artists Zoravia Bettiol and Vera Chaves Barcellos. The exhibit will be opened by the President Elect of Brazil.24

Em relação aos Estados Unidos, temia-se a perda do apoio ao governo, caso esse viesse a ser realmente entendido como uma ditadura. Nesse sentido, o Baci parece ter assumido um papel mais relevante e diretamente ligado à agenda política do Brasil e, assim, se tornado alvo mais constante de atenção do Itamaraty. O próprio Mario Gibson Barboza, quando embaixador em Washington D.C., ocupou-se em relatar os resultados das tratativas sobre exposições com artistas brasileiros, como foi o caso da mostra de arte na Pan-American Union, assim como as que se realizariam no Baci.

Embora não seja possível conhecer a totalidade das mostras realizadas pelo Brasil na capital dos Estados Unidos, é pouco provável que em seus primeiros anos de existência o Baci mantivesse uma agenda constante de exposições. Havia 
flexibilidade no calendário, o que possibilitava rearranjos e a inclusão de mostras, como foi o caso de Roberto Burle Marx em 1965, ano em que o paisagista brasileiro ganhou do Institute of American Architects de Washington o prêmio "Fine Arts Medal" pelo conjunto de sua obra. Consultado pela Embaixada, ele se mostrou favorável à realização de uma exposição, que foi encaixada na programação, seguindo a efeméride da premiação. ${ }^{25}$

Se, na década de 1960, a agenda foi intermitente e sem fluxo contínuo, na década seguinte o Baci teve seu momento áureo. Mesmo que previsto em seus estatutos, o espaço só passou a ter um diretor-executivo exclusivo a partir de 1970. Assim, em 27 de fevereiro de 1970, José Menache Neistein foi contratado para ocupar esse posto. Antes dele, apenas se elegia um chefe do Setor Cultural que, além de suas atribuições de primeiro secretário da Embaixada do Brasil, dirigia o Baci, sem receber qualquer outra remuneração para esta atividade ou dedicar-lhe qualquer atenção exclusiva. Neistein, que não era diplomata de carreira, mas prestava serviços ao Itamaraty, foi transferido da Missão Cultural em Assunção para a capital estadunidense e lá permaneceu até 2007, quando a instituição fechou suas portas.

Ao que parece, os diplomatas acumulavam funções, e a agenda do Baci nos anos 1970 implicava um volume considerável de compromissos, pois eram realizadas em média oito mostras anuais de arte, cursos regulares de português, concertos de música, seminários relacionados à cultura e à literatura brasileiras; ${ }^{26}$ também se concediam, mesmo que de modo intermitente, bolsas de estudos para o Brasil destinadas aos alunos do Baci. Contudo, é pouco provável que apenas o volume de trabalho tenha motivado a transferência de Neistein do Paraguai para os Estados Unidos.

Primeiramente, pode-se relacionar a retirada paulatina de grande parte dos congressistas norte-americanos do conselho do Baci, fato notável a partir dos anos de 1970, à nova agenda política internacional, movida pela cena interna dos Estados Unidos e pela Guerra no Vietnã. Desse modo, se no início de sua história, o Instituto foi acompanhado de perto por alguns setores do governo dos Estados Unidos, pela importância dada a América Latina, no final da década de 1960, não apenas com o fim da Aliança para o Progresso, mas também pelos novos rumos da política do país, há uma alteração no eixo geográfico dos interesses. Nesse sentido, os reais motivadores para a transferência de Neistein estariam relacionados não apenas a fatores da própria cena brasileira, mas também ao interesse cambiante dos Estados Unidos, como se verá mais adiante.

Para aprofundar a análise nesse sentido, importa pensar na figura estratégica de Neistein e na sua relação com o meio diplomático. No final dos anos 1960, o crítico encontrava-se em Viena, fazendo seu doutorado, quando se aproximou do meio diplomático brasileiro. Nesse mesmo período, Mario Gibson Barboza era embaixador (entre dezembro de 1962 a novembro de 1966), e Neistein chegou a prestar serviços para o posto do Itamaraty. ${ }^{27}$ 
Em dezembro de 1966, Barboza foi designado para a Embaixada do Paraguai e convidou Neistein para se encarregar do Instituto Cultural em Assunção, onde permaneceu por três anos. Pela competência demonstrada nessa função, notadamente pela proximidade com Lívio Abramo, ${ }^{28}$ foi transferido para Washington D.C. pouco tempo depois. Não por acaso, Mário Gibson Barboza ocupava nesse momento o cargo de ministro das Relações Exteriores (19691974). Ou seja, se na capital dos Estados Unidos a instituição demandava maior profissionalização, a capacidade de Neistein seria igualmente conveniente para a política exterior brasileira. Afinal, no fim da década de 1960, o Brasil precisava minimizar os efeitos negativos dos relatos dos exilados e banidos políticos no exterior. Iniciaram-se campanhas de repúdio e de condenação à ditadura, o regime militar se viu obrigado a reagir ao que chamou de "campanha difamatória dos guerrilheiros comunistas". Entre as estratégias para rebater essa percepção, estaria o estímulo à realização de mostras de artistas brasileiros no exterior como forma de demonstrar a existência de "liberdade de expressão" no país. Esse expediente parece ter sido bastante sutil e silencioso, pois até artistas que se opuseram à ditadura buscaram auxílio para mandar obras para mostras no estrangeiro. Mesmo que o Itamaraty fosse composto por diplomatas de variadas posições ideológicas e posturas individuais durante a ditadura, não se pode negar que a instituição, como parte do aparato institucional, apoiou o regime militar e levou adiante sua política externa. Como já se registrou muitas vezes, a falta de uma diretriz clara permitiu a diplomatas tomarem a iniciativa de mostras e programações, mas esse espaço era encampado por uma política de mão única, voltada à autoimagem do país.

Rubens Ricupero, diplomata responsável pela Divisão de Difusão Cultural do Itamaraty entre 1971 e 1974, revela que essa sessão trabalhou muito próximo da Assessoria Especial de Relações Públicas (Aerp) e que houve nesse período incentivos por parte do governo para a realização de mostras de arte no estrangeiro. Porém, segundo ele, mesmo assim trabalhava-se sob restrições, pois havia uma lista do Serviço Nacional de Informação (SNI) com nomes de artistas, escritores e intelectuais que não poderiam receber subvenções do Ministério das Relações Exteriores. ${ }^{29}$ Os diplomatas, afirma ainda, para dissimular essas restrições, criaram um subterfúgio: a concessão da Ordem Rio Branco, medalha do Itamaraty, a alguns artistas, o que possibilitava remover seus nomes da relação do $\mathrm{SNI}{ }^{30}$

Nesse panorama de ações e iniciativas apenas aparentemente discrepantes, a transferência de Neistein do Paraguai para o posto de diretor geral do Baci parece estar associada à estratégia do Brasil em apresentar uma imagem afirmativa no exterior, por meio das artes. Já em seu primeiro relatório, escrito em 1970, o recém-empossado diretor do Baci informou que o Ministério cuidou de perto das mostras de artistas enviadas para o estrangeiro:

The general program of the Institute's activities in 1970 could not be planned in advance, due to the change in the method of financing the activities, con- 
trary to the application of the annual cultural allotment of the Embassy, as in previous years. Each one of the activities was examined, approved and funded individually during the year by the Ministry of Foreign Affairs with the approval of the Embassy. A proposed program of activities has been developed in conjunction with the Cultural Department of the Embassy for submission to the Foreign Ministry where it will be studied. [...] The Institute in the past has received the allotment of the cultural department of the Embassy for its activities. With the change in the method of funding activities during 1970 each project is studied individually. ${ }^{31}$

A submissão preliminar da agenda do Baci à Embaixada em Washington e ao ministério era uma prática comum. No entanto, Neistein comunica uma excepcionalidade, pois a anuência da programação ocorreu de modo pontual e nominal, e não generalizada como de costume.

Observando a programação do Baci de 1970, vê-se que houve somente quatro exposições: Yolanda Mohalyi, Sergius Erdelyi, Raimundo Colares e Kazuo Wakabayashi. A mostra de Mohalyi foi subsidiada diretamente pelo Ministério das Relações Exteriores, e a de Erdelyi, paga pelo próprio artista que vivia nos Estados Unidos. Já a de Colares, vinculada ao recebimento do prêmio Standard Eletric, oferecido pelo Salão Esso, no Rio de Janeiro, foi parcialmente financiada pela United State Information Agency (Usia) e pelo próprio Baci. No caso dos trâmites e dos custos da exibição do pintor Wakabayashi, não há informações. ${ }^{32}$ Cabe apenas sinalizar que, tanto ele como Mohalyi foram presenças constantes na programação em Washington D.C. e suas obras estavam entre as mais vendidas no Baci. A comercialização ocorria quando desejada pelo artista e a instituição recebia $20 \%$ do valor da transação. Segundo depoimento de Neistein, os preços costumavam ser similares aos praticados no Brasil, ou até um pouco inferiores, como nos casos de Manabu Mabe, Yolanda Mohalyi e Tomie Ohtake, que, muitas vezes, aceitaram um pequeno abatimento com o intuito de ampliar o público para seus trabalhos. ${ }^{33}$ Ainda segundo ele, uma das maiores decepções foi a exposição de xilogravuras e desenhos de Livio Abramo, em 1974. Não apenas o vernissage contou com poucas pessoas, como quase não houve venda dos trabalhos expostos. ${ }^{34}$ Neistein também se orgulha de ter realizado as primeiras mostras de Yolanda Mohalyi, Tomie Ohtake e Mira Schendel (1973) nos Estados Unidos. ${ }^{35}$

No que diz respeito à comercialização dos trabalhos expostos, sabe-se que os compradores eram basicamente brasileiros residentes nos Estados Unidos, estadunidenses com negócios na América Latina, diplomatas e funcionários da Embaixada, que adquiriam trabalhos para as suas próprias coleções, assim como para presentear oficialmente autoridades. Nesse caso, a função de representar imagens de brasilidade teria se apoiado nos estereótipos imagéticos do país. $\mathrm{O}$ caso das gravuras de Zoravia Bettiol, por exemplo, com suas imagens de uma etérea cultura popular, torna evidente tal tendência, pois foi uma das campeãs de venda no Baci. 
Percebe-se, no entanto, a dificuldade de se precisar um sistema claro, uma estratégia de atuação planejada, embora sempre se possa explicitar a necessidade difusa de acertar as contas com a opinião pública interacional por meio de uma pretensa liberdade de expressão artística. Apesar da importância do Baci para o Itamaraty em diversas ocasiões, não foram desenhadas diretrizes ou propostas explícitas para a instituição. É possível, no limite, identificar estratégias específicas a partir da análise de eventos e reconhecer marcas individuais de diplomatas que passaram pela Embaixada do Brasil. Nesse sentido, a análise aqui proposta pode, ao se aproximar de exemplos pontuais, estabelecer padrões de atuação, reincidências discursivas sutis, que, se não se estabelecem como um método, explicitam linhas de atuação matizadas. A estratégia de estudar mais detidamente alguns eventos precisos possibilita, mesmo que de forma hipotética, estabelecer aspectos gerais dessa política e conhecer melhor suas dimensões.

$\mathrm{O}$ primeiro caso a ser analisado refere-se à mostra de Nelson Leirner, denominada The Rebellion of the Animals: a series of drawings, exibida em 1974, quando João Augusto de Araújo Castro era o embaixador em Washington. ${ }^{36}$ Representantes militares do governo brasileiro, presentes na abertura, não exprimiram qualquer insatisfação ou constrangimento diante dos cogumelos que se transmutavam em imagens fálicas e opressivas, ou de objetos, como tesouras, cabides e espetos, que se assemelhavam a instrumentos de tortura. O conteúdo abordava diretamente o momento político vivido no Brasil, o que constava inclusive no texto de Flávio Mota publicado no catálogo que acompanhava a mostra:

Individualidades monstruosas, em espaços opressivos, onde habitam fantasmas medievais de nosso tempo - cavaleiros de um suposto Apocalipse explodem as próprias entranhas. É da mão do nosso tempo, nestas estruturas mais antigas, ancestrais, mas tão presentes, tão ainda de hoje. [...] O desenho voltou sobre a folha de papel, mas também sobre os conflitos humanos do momento histórico. (Motta, 1974)

Os títulos são explícitos - "Renascimento de uma ideia"; "A rebelião"; "Encurralados"; "Torturados"; "Deportados"; "Corpos abandonados"; "Corpos não identificados" - na referência, sem artifícios metafóricos, à história recente do Brasil. Isso ficou longe de provocar, no entanto, qualquer incômodo nos representantes do regime militar que lá estavam. Talvez porque o conjunto já fora anteriormente exibido na Universidade do Texas sem chamar a atenção da crítica para o seu real conteúdo. ${ }^{37}$

Outro caso digno de nota, inclusive pela ausência característica de método quanto ao que era ou não liberado, foi o episódio de censura que ocorreu em 1982, por ocasião da exposição Madalena Schwartz. Neistein a convidara pessoalmente, sendo que a mostra deveria incluir

[...] 50 ou 60 retratos de personalidades da vida pública brasileira, em vários setores, bem como de tipos anônimos do povo, todos eles destinados 
a transmitir a variedade e a riqueza expressiva do homem brasileiros, numa exposição que se intitularia "Rostos Brasileiros". [...] A mostra em apreço seria realizada sob auspícios do Itamaraty. ${ }^{38}$

Provavelmente motivada pelo convite, ela solicitou à Assessoria da Presidência da República “autorização para fotografar o casal presidencial, Sua Excelência o presidente da República, João Batista Figueiredo, e sua Excelentíssima esposa, D. Dulce Figueiredo, sem o qual minha exposição estará incompleta”. Na carta, ela explicitava o formato da mostra que havia sido acordado com o diretor do Baci: “60 retratos, divididos entre 60\% de personalidades importantes da nossa vida pública e $40 \%$ de rostos típicos, anônimos”. Informava ainda que o "trabalho estava sendo apreciado pela Secretaria de Cultura do Estado de São Paulo, pelo Conselho Nacional de Amparo à Pesquisa e pela Kodak do Brasil”. ${ }^{39}$ Provavelmente, foi esse pedido que suscitou averiguação pelo Sistema Nacional de Informação sobre a fotógrafa, assim como sobre o próprio José Neistein, sendo a resposta negativa quanto à aprovação de ambos os investigados. ${ }^{40}$

Antes mesmo da abertura da mostra no Baci, o embaixador Antônio Francisco Azeredo da Silveira ${ }^{41}$ mandou fechá-la por ser incompatível com a realidade do país. ${ }^{42}$ Segundo Neistein, o fato foi motivado não apenas pela ideia de expor o presidente, mas também pela presença de considerável número de rostos de negros na mostra. ${ }^{43}$ Repetia-se, mais uma vez, a posição da diplomacia em querer apresentar o Brasil como "civilizado", portanto, "branco". Também o caso do filme Orfeu negro, que o Ministério das Relações Exteriores se recusou a inscrever no Festival de Cannes em 1959, tem argumentos bastante explícitos: uma imagem negativa por apresentar atores negros das favelas do Rio de Janeiro. O filme acabou sendo inscrito pela França, recebendo em 1960 não somente a Palma de Ouro na cidade francesa, como também o Oscar de Melhor Filme Estrangeiro.

Como os convites para a abertura da mostra de Madalena Schwarz já haviam sido remetidos, foi organizada uma mostra-relâmpago com as próprias obras coleção do Baci, para não receber o público com as paredes vazias. ${ }^{44}$

As dimensões desse caso podem ser mais bem compreendidas pela exposição realizada em 1983, no Museu de Arte de São Paulo (Masp), pois, segundo Jorge Schwartz, filho da fotógrafa, tratava-se do mesmo conjunto de trabalhos. ${ }^{45}$ Segundo o repórter Fernando Durão, a exposição apresentava 70 fotografias em branco e preto (tamanho $30 \times 40 \mathrm{~cm}$ ) em que figuravam $60 \%$ de artistas, intelectuais, cientistas e políticos, e 40\% de anônimos, ${ }^{46}$ proporções já acordadas entre a fotógrafa e Neistein. O então diretor do museu, Pietro Maria Bardi, assim se referiu aos trabalhos:

[...] deveria dizer amostragem de tipos, os quais multiplicados à enésima potência na mistura de raças, representam o aglomerado demográfico do Brasil. Madalena escolheu sem escolher: acertou o povo de qualquer origem, os humildes e os que se tornaram famosos no olimpo do esporte 
ou no fechado setor da cultura, recompondo o seu Brasil. Cada um pode encontrar e representar o que vê, crê e ama. Ela o viu, nele acreditou e o amou à sua cordial maneira. ${ }^{47}$

$\mathrm{O}$ conjunto de rostos miscigenados em nada corresponde à tipologia da elite branca brasileira, sempre presente no corpo diplomático do país. Como as imagens da fotógrafa ofereciam resistência a esse imaginário, entende-se o motivo da censura: a pobreza e a miscigenação no rosto do povo brasileiro.

O mesmo conjunto de retratos retornaria aos Estados Unidos em uma turnê $\hat{e}^{48}$ que pôde ser vista entre 29 de março e 25 de abril de 1984, no Martin Luther King Jr. National Memorial Foundation em Washington, D.C. O retorno da exposição a esta cidade após o incidente de reprovação do diplomata brasileiro não foi casual. Segundo Jorge Schwartz, o lugar onde ela efetivamente ocorreu era bastante prestigioso, se comparado ao Baci. ${ }^{49}$

Por ocasião da mostra no Masp, foi incluído no catálogo um texto de José Neistein, no qual este é apresentado como crítico de arte, editor contribuinte do Latin American Handbook em Washington D.C. e autor de Feitura das Artes, sem qualquer menção ao seu posto no Baci (Schwartz, 1983). Essa atitude pode ser interpretada como um ato de coragem, pois, mesmo em se tratando do fim do regime militar e não sendo ele um diplomata de carreira, ocupava um cargo e, por isso, encontrava-se em posição vulnerável.

Outro caso que nos oferece o perfil conservador e restritivo da agenda do Baci é a mostra do pintor Darcy Penteado. Analisando as fotografias das obras que seriam expostas, o então embaixador escreveu confidencialmente à Secretaria de Estado que seria conveniente recomendar ao artista que:

[...] evite a remessa de trabalhos passíveis de despertar polêmica de fundo religioso. O caráter semioficial do instituto não lhe permite expor obras de impacto. Além disso, Washington é ainda um centro pequeno e conservador [...]. A obra de inspiração religiosa de Darcy Penteado se sentiria mais a vontade, por exemplo, em Nova York, [...] mas nunca patrocinada pelo governo. ${ }^{50}$

Apesar desses problemas, Neistein fez questão de afirmar que sempre houve autonomia em seu trabalho e foram raras as vezes em que precisou incluir algum artista ou músico por solicitação de algum diplomata. ${ }^{51}$

De modo geral, como costumam ser as atividades culturais diplomáticas, a programação das mostras do Baci apresentava um perfil sem ousadia e os espaços de suas sedes tampouco eram de grandes proporções. Mostras de gravuras eram constantes, tanto de exposições coletivas quanto individuais. Nesse processo, é bom lembrar que Neistein manteve contato direto com a cena brasileira; anualmente, quando passava o período do verão do hemisfério norte gozando de suas férias no Brasil, visitava mostras e atelievs para fazer sua programação. Como na grande maioria das vezes as gravuras não eram emolduradas, facilitava-se ainda mais o transporte. A gravura possuía um lastro com larga tradição no Brasil e 
com reconhecido valor internacional, fato inclusive utilizado como argumento pelos diplomatas: "Brazil has a strong tradition on the art of engravity. Most of our prizes and awards at the Biennal of Venice, the Biennal of Young artists in Paris and others have been given to engravers". ${ }^{2}$ Assim, duas condições se sobrepõem: a qualidade da gravura brasileira, atestada pelo seu reconhecimento internacional, e a viabilidade financeira de sua exposição.

O desinteresse do Itamaraty pelo Baci parece ter se acentuado mais fortemente no final da década de 1970 e pode ser mais bem compreendido pelas dificuldades financeiras que se tornaram recorrentes e se expressavam na dificuldade com o pagamento do aluguel, dos salários ${ }^{53} \mathrm{e}$ das taxas de manutenção do imóvel. Em diferentes anos, a situação permaneceu a mesma:

To be able to improve its financial situation, in the face of a significant reduction in the anual allotment provided by the Brazilian Government, Baci should seek out the support of the private sector and other local sources in order to supplement its financial needs. For the matter, BACI should be working on a fund raising membership campaign, that is strongly aimed at the private sector, adhering to special membership categories. ${ }^{54}$

Apesar de tudo, era ainda a Embaixada que acabava por socorrer a instituição em casos extremos:

[...] em razão dos problemas que estão provocando o atraso na assinatura do convênio de subvenção social entre essa embaixada e aquele instituto cultural $[\ldots]$ não pode o governo brasileiro deixar de reconhecer que a continuada inadimplência do BACI pode vir a comprometer a imagem do Brasil nos Estados Unidos. ${ }^{55}$

Ao longo dos anos, proporcionalmente, a ausência do Itamaraty no gerenciamento do Baci favoreceu a autonomia de José Neistein, ainda que houvesse subordinação e dependência financeira da instituição. A flexibilidade na administração era favorecida por ser a instituição uma entidade jurídica dentro das leis de Washington D.C. Durante seu período de funcionamento, foram criados subterfúgios para contornar os orçamentos limitados, como a realização de inúmeros convênios e apoios privados. Esse desejo por encontrar parcerias privadas já se notava no momento da fundação do Instituto, quando se pretendeu atrair empresas interessadas em fazer negócios com o Brasil, conforme mencionado anteriormente. Sem chegar a ser um órgão realmente autofinanciado, e mesmo tendo perdido um tanto de seu papel entre personalidades norte-americanas por conta de reorganizações geopolíticas, o Baci manteve sua ordenação original.

Em situações pontuais, como para adequar a nova sede alugada em 1985, ${ }^{56}$ realizou-se um leilão com o acervo da instituição (1984). Nas palavras de Neistein:

In order to raise additional funds to continue the installation work in its new auditorium-gallery, and therefore to be able to offer its members and the community at large, a program of activities of greater variety, Baci decided 
to conduct a silent and live auction of some of its art works belonging to the Institute's permanent art collection. ${ }^{57}$

Neistein, no relatório de 1985, informa ainda que foi arrecadado o valor de U\$10,500. O mesmo texto avisa que o setor industrial têxtil de São Paulo contribuiu na compra de um piano Grand Steinway, casualmente no mesmo valor de U\$10,500. Para o ano 2006, por exemplo, foram enviados pelo Ministério brasileiro U\$150,000, contrastando com a soma pedida de U\$250,000..$^{58}$ Em 2006, o Ministério das Relações Exteriores sugeriu a locação de espaço menor como forma de diminuição dos custos. Esperava-se que em 2007 o Baci cuidasse do custeio integral de seu aluguel, o que não ocorreu.

Acompanhar a história do Baci nos permite perceber a inexistência de um projeto linear pautado pelo Itamaraty para as áreas artísticas e culturais. $\mathrm{Na}$ opinião do diplomata Edgard Telles Ribeiro, tal política se inviabiliza pela "falta de coordenação entre órgãos responsáveis pelo assunto, cuja origem, por sua vez, remonta às baixas prioridades de que o tema se reveste internamente no país". Além disso, segundo ele, a constante troca nas chefias dos setores culturais e nos postos e a escassez de recursos destinados à difusão cultural no exterior dificultam tentativas de se desenvolver projetos continuados (Ribeiro, 2011, p.89). O espaço poderia ter sido um canal potente de apresentação de artistas brasileiros, o que na realidade não ocorreu, sobretudo porque o Itamaraty não estabeleceu diretrizes para a instituição tornando-a vulnerável aos interesses diplomáticos individuais, ou servindo à precipitadas ações de propaganda política, sem coordenação sistemática ou aporte conceitual/teórico claro. Quando deixou de ser anteparo às funções diplomáticas, tampouco houve aproximação com o meio artístico brasileiro mais jovem e efervescente.

Já em 1966, Vasco Mariz, então chefe da Divisão de Difusão Cultural do Itamaraty, alertava para a necessidade de o diplomata estar ligado à cena de seu próprio país para poder melhor representá-lo, como atesta este registro:

Por mais que leia jornais, revistas e livros, o diplomata no exterior se desatualiza cada dia e, ao fim de poucos anos, perde a perspectiva da escala de valores artísticos e literários, perspectiva que só mesmo a presença mais ou menos longa no Brasil pode oferecer. Fica, assim, impossibilitado de seguir as oscilações naturais da produção intelectual de seu país ou de dizer, a qualquer momento, quais os nomes realmente representativos da cultura brasileira ou que merecem divulgação ou apoio oficial no exterior. (Mariz, 1966, p.9)

Esse parece ter sido o caso de Neistein. Sua longa permanência como diretor do Baci, de 1970 a 2007, deveu-se ao corpo diplomático do Itamaraty reconhecer sua competência. Profissional culto e erudito, possuía expressivo conhecimento sobre as artes e a cultura brasileira. Ele também buscou, para além de suas atribuições como diretor, construir vínculos com universidades e centros de ensino de língua e de cultura brasileira nos Estados Unidos. Com 
frequência, era convidado para seminários e conferências, fato que não o fez depender exclusivamente do Baci. Na década de 1990, por exemplo, foi professor visitante na Universidade da Pensilvânia. Mas, se sua continuidade na instituição lhe foi garantida por um sólido passado cultural, seu capital de atualização a respeito da cena artística brasileira não ocorreu na mesma proporção. Malgrado seus esforços individuais, parece que não havia um respaldo maior. Sempre com orçamentos limitados, realizou mostras convencionais e, a partir da década de 1980, raramente houve nomes de peso da arte contemporânea na agenda de mostras da instituição. Centralizado na figura de seu diretor, o Baci parece ter perdido a capacidade de agenciamento coletivo. Seu diretor, considerado figura competente nos meios diplomáticos, apesar do apoio que havia recebido de Mário Gibson Barboza, um dos homens de maior confiança do General Médici, não deixou de ser alvo de investigação. No dia 24 de agosto de 1983, o Centro de Informações do Ministério da Justiça apresenta os seguintes dados sobre ele e o Baci:

[...] homossexual declarado, que recebe dentre outras vantagens, o salário mensal de U\$7000,00 (sete mil dólares), além de duas passagens aéreas para vir ao Brasil anualmente, sendo ainda assessorado por cerca de 10 "professores", todos pagos pela Embaixada Brasileira em Washington. Referida instituição não tem sido utilizada para fins propostos, servindo atualmente de ponto de encontro de homossexuais americanos e brasileiros nos EUA. ${ }^{59}$

As informações deixam claro que não apenas critérios técnicos norteavam as indicações, mas também outros critérios difusos quanto à imagem diplomática do país. O diplomata Alberto V. da Costa e Silva, chefe do DCC do Itamaraty, refutou todas as acusações feitas à instituição e ao seu diretor. Afirmava que o Baci

[...] sempre recebeu entusiasmado apoio de todos os Embaixadores brasileiros que passaram por Washington: Vasco Leitão da Cunha, Mario Gibson Barboza, Mozart Gurgel Valente, João Augusto de Araújo Castro, João Baptista Pinheiro e Antônio Francisco Azeredo da Silveira. Desde Mozart Gurgel Valente, todos prestigiaram o Professor José Menache Neistein cuja capacidade de trabalho, cultura e competência já havia sido testada amplamente em Assunção do Paraguai, onde o Professor Neistein servira, no centro de estudos brasileiros, sob ordens do Embaixador Mario Gibson Barboza. ${ }^{60}$

Certamente, deve-se considerar que em 1983 os serviços dos órgãos de inteligência, as perseguições e a censura estavam enfraquecidas se comparados aos momentos mais difíceis da ditadura militar. Mesmo assim, nesse episódio interessa observar o tom enfático da salvaguarda, o que permite mesurar o lugar do Baci e de seu diretor na perspectiva do Itamaraty. Na resposta, o diplomata destacou as qualidades profissionais de Neistein, que iam além de sua atividade no Baci, pois ele era editor do Handbook of Latin America Studies da Bibliote- 
ca do Congresso de Washington. ${ }^{61}$ Ressaltava ainda que, após a chegada dele, a instituição passou a colaborar diretamente com os cursos de português das Universidades Johns Hopkins, Georgetown e Católica de Washington D.C. O texto enumerava ainda as contribuições da instituição à qualidade do ensino da língua e salientava a atuação de Hayddée Magro, "reconhecida como uma das melhores especialistas em Português dos Estados Unidos". Além disso, os quatro mil volumes da biblioteca serviam de apoio aos estudiosos daquele país.

A intercessão do diplomata salientava ainda que o espaço, ao contrário do que o SNI afirmava, era frequentado pela comunidade brasileira de Washington D.C. e que essa havia solicitado a criação do curso de Geografia e História do Brasil. Ademais, o texto apresentava os aspectos contratuais de Neistein: ele gozava de estabilidade, seu salário era de U\$3,640.00 e suas passagens para o Brasil eram custeadas por ele mesmo. ${ }^{62}$

Se na década de 1960 houve um peso maior de interesses dos Estados Unidos em apoiar centros de cultura como o Baci, na década seguinte foi a vez de o Brasil se utilizar dele para apresentar uma imagem oficial que contrastava com os relatos dos exilados. Nesse sentido, a instituição pode ser observada como contraponto à política interna e à tensão vivida naqueles anos de chumbo no Brasil. Após os inúmeros sequestros de diplomatas estrangeiros no país, o Ministério das Relações Exteriores e sua diplomacia empenharam-se em oferecer no estrangeiro uma imagem de Brasil que zelava pelos valores artísticos, livres de restrição ou de censura. Para efetivar essa política, conforme os dados aqui discutidos, o Baci precisou se tornar mais profissional. A chegada de José Neistein, então, foi providenciada, sendo esse o período áureo da instituição. Nessa década, a organização da agenda de mostras e sua divulgação foram mais cuidadosas, apesar da oscilação apontada entre projeto institucional e iniciativa particular. Foram produzidos catálogos dessas mostras, cuidadosamente arquivados pelo Baci, atualmente abertos para consulta na University of Massachussetts, em Dartmouth. Por fim, após constantes agonias financeiras, o fechamento do espaço foi inevitável. Neistein liquidou o patrimônio do Baci para quitar parte das dívidas, pois tampouco a Embaixada ou o Itamaraty preocuparam-se com esse encerramento. $\mathrm{O}$ descaso por pouco não envolveu a memória da instituição, pois tanto a biblioteca como o arquivo foram negligenciados pelos representantes do governo brasileiro. Os livros foram parcialmente vendidos ou então doados. O arquivo não se dissipou graças aos esforços de Maria Angela Leal, Assistant Curator da The Oliveira Lima Library da The Catholic University of America, cujo empenho levou à aquisição do arcevo como um todo pela University of Massachussetts, em Dartmouth.

Se a América Latina foi deixando de ser foco das atenções da política externa dos Estados Unidos já na década de 1970, em 2007, o governo do presidente Lula já não considerava Washington o seu único centro de interesses. Novas Embaixadas e postos consulares foram abertos e fortes parceiros comerciais 
entravam em cena, como a China, por exemplo. A soma despendida para um único posto como o Baci não mais se justificava, seja pela pouca visibilidade e repercussão de suas atividades, seja porque arte e cultura, tradicionais caminhos de aproximação, eram dispensáveis entre parceiros já conhecidos no mundo globalizado. Assim, não parecia haver mais motivos para manter o Brazilian-American Cultural Institute ou estabelecer uma política de difusão cultural específica para os Estados Unidos, haja vista outros museus e instituições cuidarem dessa tarefa. Afinal, não somente os centros binacionais perderam o protagonismo como espaços relevantes, como a diplomacia cultural praticada no século XXI parece prescindir deles.

\section{Notas}

1 Essa pesquisa só pôde ser realizada com o apoio financeiro da Fapesp e do CNPq. Parte das reflexões aqui expostas constam dos anais do $22^{\circ}$ Encontro Nacional da Anpap ocorrido em 2013.

2 Embaixada do Brasil, Washington (D.C.), EUA. [Carta-telegrama] 19 abr. 1963, [de] Roberto de Oliveira Campos [para] Ministério das Relações Exteriores, Brasília (DF), Brasil. lp. Solicita estatutos para o Instituto Brasil-Estados Unidos de Washington (D.C.). Localizada no Arquivo do Itamaraty em Brasília (DF).

3 A Política Externa Independente foi projeto dos governos Jânio Quadros e João Goulart que procuraram manter o Brasil independente da bipolaridade Estados Unidos $\mathrm{x}$ União Soviética e, com isso, ter uma política externa internacional mais livre.

4 Bulletin. Washington (D.C.). Brazilian-American Cultural Institute, n.01, jan. 1966, s.p. Localizado na Claire T. Carney Library, University of Massachussetts, Dartmouth. Embora publicado em 1966, o texto do presidente já havia aparecido em documentos elaborados em 1963.

5 Embaixada do Brasil, Washington (D.C.), EUA. [Carta-Telegrama.] n. 1284 (5), maio, 2004. Ip. Envia informações sobre o Brazilian-American Cultural Institute. Localizada no Arquivo do Itamaraty em Brasília (DF).

6 Desde o início, o orçamento do Baci era motivo de preocupação de seu Conselho Diretor. Sabe-se, no entanto, que, além da contribuição dos associados, houve a sugestão de participação de empresas norte-americanas no orçamento, embora não tenha sido possível confirmar a efetivação dessa prática. "Congressman Morse suggested that he and Congressman Irwin write a letter to all the American Companies with interest in Brazil soliciting funds. Mr Morse suggested that Mr Hasslocher and Mr Ouro Preto join him in setting up a date for a lunch with Mr Washburn, a friend of Mr Morse who is a Public Relations expert and who could assist them in drafting the letter for fund raising" In: Minutes of The Eighteenth Meeting of The Board of Directors of The Brazilian American Cultural Institute. Jan. 12. 1967, p.4. Localizado na Claire T. Carney Library, University of Massachussetts, Dartmouth.

7 No primeiro boletim da instituição constam como membros do Board of Directors: Charles G. Fenwick (Chairman), F. Bradford Morse (Congressman), Maurício C. Bicalho, Donald Irwin (Congressman) e Luiz A. Cunha (Executive Director). Ver: Bul- 
letin. Washington (D.C.): Brazilian-American Cultural Institute, n.1, jan. 1966, s.p. Localizado na Claire T. Carney Library, University of Massachussetts, Dartmouth. F. Bradford Morse, deputado pelo Estado de Massachussetts, foi eleito membro do conselho em outubro de 1965 e figura nas atas até 1972, ano em que foi nomeado pelo presidente Nixon para o posto nas Nações Unidas em Nova York. Donald Irwin não aparece mais como membro na reunião de 1970. Também John Brademas, deputado pelo Estado de Indiana, recebeu convite para ingressar no Board of Directors em carta datada de 7 de fevereiro de 1969. Em 1972, Brademas, por impossibilidade de agenda, indicou Charles Moffitt, de sua equipe, para participar do conselho em seu lugar. Consta em ata que foi substituído pelo diplomata Niles W. Bond, cônsul dos Estados Unidos em São Paulo entre 1964-69. Este foi membro do conselho em 1972, 1973, 1974 e em 1975 tornou-se o seu presidente, permanecendo até 1985, quando foi substituído por Félix Grant. Nesse conjunto de nomes, deve-se acrescentar Abbot Washburn, presidente honorário na década de 1970. Por serem mais políticas, as nomeações para o ingresso no Board costumavam ficar a cargo da própria Embaixada.

8 Desde a fundação, a estrutura da instituição dividia-se em Board of Directors (com a eleição de um Chairman) e Board of Advisors. Havia também um quadro de sócios que contribuía financeiramente e elegia seus representantes no Conselho Diretor. O cargo de Executive Director fora criado em 1966, ao mesmo tempo em que se extinguia a função de General Secretary. In: Bulletin. Washington (D.C.). Brazilian-American Cultural Institute, n. 1, Jan. 1966, p.5. Localizado na Claire T. Carney Library, University of Massachussetts, Darmouth.

9 Brazilian-American Cultural Institute, Washignton (D.C.), EUA. Report. 1985, p.13: "Counselor Lauro Moreira in a series of telephone and telegram exchanges were able to secure a \$19,000 donation from Norberto Odebrecht S. A., as well-known Brazilian construction company" (José M. Neistein). Localizado na Claire T. Carney Library, University of Massachusetts, Dartmouth. Já em 1992, foram arrecadados U\$90,000.00 entre as empresas Petrobrás (U\$10,000.00), Construtora Odebrecht (U\$20,000.00), Vasp (U\$20,000.00) e Banco do Brasil (U\$40,000.00). Também as mensalidades/ contribuições dos sócios sofreram acréscimos e, com o passar dos anos, a receita dos cursos de português tornou-se preciosa fonte de recursos.

10 Gabinete da Presidência da República. Serviço Nacional de Informação. Levantamento de pessoas. Referência: DDC/75/540.31(00), 30 abr. 69, s.p. Arquivo Nacional, Brasília, ACE 51341/69.

11 Gabinete da Presidência da República. Serviço Nacional de Informação. Levantamento de pessoas. Referência: DDC/75/540.31(00), 30 abr. 69, s.p. Arquivo Nacional, Brasília, ACE 51341/69.

12 Gabinete da Presidência da República. Serviço Nacional de Informação. Levantamento de pessoas. Referência: DDC/75/540.31(00), 30 abr. 69, s.p. Arquivo Nacional, Brasília, ACE 51341/69.

13 Ministério das Relações Exteriores. Divisão de Segurança e Informações. Registra informações sobre Regina Vater. Referência: DSI/1802, 31 ago. 1972. Arquivo Nacional, Brasília, ACE 50018/72.

14 Ministério das Relações Exteriores. Divisão de Segurança e Informações. Pedido de endereços de artistas brasileiros. Referência: DSI/ 2754, 11 jul. 1977. Embaixada do Brasil em Roma, Itália. 
15 Secretaria de Estado das Relações Exteriores, Rio de Janeiro (RJ), Brasil. [Carta-telegrama] n.96, 19 mar. 1969, [para] Consulado-Geral de Nova York, EUA. Envia Programação cultural de 1969. Referência: DDC/DAS/540.31(22). Localizada no Arquivo Itamaraty em Brasília (DF).

16 Lauro Soutello Alves. [Carta-telegrama] 8 abr.1969, do Consulado Geral de Nova York. Informa sobre Exposições de Artes Plásticas em Nova York, DDC/ DAS $/ 540.31(22)$.

17 Secretaria de Estado das Relações Exteriores, Rio de Janeiro (RJ), Brasil. [Telegrama] 6 nov. 1969, [para] Consulado-Geral de Nova York, EUA. Envia Programação de Artes Plásticas, DDC/DAS/540.31(22). Localizado no Arquivo Itamaraty em Brasília (DF).

18 Os títulos da pinturas: A dog's dream; I still can see I still can say; America: the burned hero; Murder your love; The soldier: what he thinks; Hero; A trunk; Self-portrait for a counter-attack; Letter; Blowing; Paris 3; Paris 2; Untitled; Untitled. E dos desenhos: She; Airless; Command; Burning away from fire; The wrong story; A small gift for your night: masked face; In bed; The spetacular attack from the flying ray. Ver: Secretaria de Estado das Relações Exteriores, Rio de Janeiro (RJ), Brasil. [Carta-telegrama]. n.158, 21 maio 1969. Envia sugestão de exposição, DDC/DAS/540.31(22).

19 Secretaria de Estado das Relações Exteriores, Rio de Janeiro (RJ), Brasil. [Telegrama.] 2 maio 1969, [de] Lauro Soutello Alves [para] Consulado Geral de Nova York. Envia informe sobre Exposição de Artes Plásticas em Nova York/Pintor Antonio Dias, DDC/DAS/540.31(22). Localizado no Arquivo Itamaraty em Brasília (DF).

20 Antonio Dias. Arts Magazine, september/october 1969, v.44 n.1, p.60. Nessa resenha da mostra, que era acompanhada da imagem da obra Murder, Hero, Love de 1965, constavam os prêmios que Dias havia conseguido na Bienal de Paris em 1965, assim como na Bienal de Lignano em 1968.

21 A Galeria Bonino, fundada em Nova York em outubro de 1962, foi um espaço significativo para exibição de artistas latino-americanos. Possuía sedes também em Buenos Aires, Rio de Janeiro e Londres. Ver Angel (1988, p.238-9).

22 Cf. Camnitzer e Weiss $(2009$, p.172). ["while members of the committee distributed literature to the visitors, members of MICLA gave out 'contra ex-potos' bandaged fragments of dolls."]

23 Secretaria de Estado das Relações Exteriores, Rio de Janeiro (RJ), Brasil. [Telegrama] 31 jul. 1969, [para] Consulado-Geral de Nova York, EUA. Envia Programação de Exposições de Artes Plásticas, DDC/DAS/540.31(22). Localizado no Arquivo Itamaraty em Brasília (DF).

24 Minutes of The Eighteenth Meeting of The Board of Directors of The Brazilian American Cultural Institute. January 12, 1967, p. 4. Localizado na Claire T. Carney Library, University of Massachussetts, Darmouth.

25 Embaixada do Brasil, Washington (D.C.), EUA. [Telegrama] 24 e 25 mar. 1965, [de] Juracy Magalhães. Informa sobre a possibilidade de realizar exposição de Burle Marx no Baci, n. 4540. Localizado no Arquivo do Itamaraty em Brasília (DF).

26 Segundo Neistein, os cursos de português eram cobrados desde o início do Instituto e, num certo momento, tornaram-se fonte significativa em seu orçamento. Outras atividades passaram a ser cobradas apenas quando a instituição viu-se em dificuldades 
financeiras (José Neistein, Entrevista concedida a esta pesquisadora em 30 de janeiro de 2012, Fairfax Village, Virgínia, EUA).

27 Mario Gibson Barboza foi embaixador em Viena entre dezembro de 1962 e novembro de 1966. Em dezembro do mesmo ano, passou a exercer a mesma função em Assunção. Entre o início de 1968 até 30 de janeiro de 1969 foi secretário geral do Itamaraty. Foi embaixador nos Estados Unidos entre fevereiro e outubro de 1969. Em seguida, tornou-se ministro das Relações Exteriores permanecendo até o final do governo Médici, em 1974.

28 É José Neistein que credita a qualidade de seu trabalho em Assunção a Livio Abramo, que lá já se encontrava antes de sua chegada (José Neistein, Entrevista concedida a esta pesquisadora por telefone em 9 de dezembro de 2015, em São Paulo).

29 Rubens Ricupero, entrevista concedida a esta pesquisadora em 5 de outubro de 2012, na Faculdade Armando Álvares Penteado (FAAP), São Paulo.

30 No entanto, apesar do depoimento do diplomata, não foram ainda localizados documentos referentes a esse expediente.

31 José M. Neistein, Anual Report 1970. Washington (D.C.). Brazilian-American Cultural Institute, 1971, p.1-8. Relatório. Localizado na Claire T. Carney Library, University of Massachussetts, Darmouth. Cabe ressaltar que o conjunto de relatórios nessa biblioteca não estão completos.

32 José M. Neistein, Anual Report 1970. Washington (D.C.): Brazilian-American Cultural Institute, 1971, p.14. Relatório. Localizado na Claire T. Carney Library, University of Massachusetts, Dartmouth.

33 José Neistein, entrevista concedida a esta pesquisadora em 30 de janeiro de 2012, Fairfax Village, Virgínia, EUA.

34 José Neistein, entrevista concedida a esta pesquisadora por telefone em 9 de dezembro de 2015, São Paulo.

35 José Neistein, entrevista concedida a esta pesquisadora por telefone em 9 de dezembro de 2015, São Paulo Yolanda Mohalyi exibiu óleos e guaches em duas mostras individuais: 1970 e 1974. Em 1985 e 2007, teve obras incluídas em exposições coletivas. Já a individual de Tomie Ohtake ocorreu em 1976. Em 1973 e 1985 participou de coletivas. E, por fim, Mira Schendel ocupou sozinha o espaço do BACI com desenhos, objetos e cadernos em 1973.

36 O embaixador João Augusto de Araújo Castro permaneceu no cargo de 1971 a 1975.

37 Nelson Leirner (1974). A mesma exposição ocorreu em dois outros espaços: University Art Museum - The University of Texas at Austin, em fevereiro/março de 1974, e no Museu de Arte de São Paulo, em maio/junho de 1974.

38 José M. Neistein, [Carta] 23 jul. 1981, São Paulo, [para] Madalena Schwartz, Brazilian Cultural Institute, Inc. Localizada no Arquivo Nacional em Brasília (DF). Pela data e o local da correspondência, provavelmente ele estava de férias no Brasil, como costumava fazer nos verões norte-americanos.

39 Madalena Schwartz, [Carta], 26 abr. 1982, São Paulo, [para] Tenente Coronel Piero Ludovico Lobbato, Chefe da Assessoria Especial da Presidência da República. Localizada no Arquivo Nacional em Brasília (DF).

40 Serviço Nacional de Informações (SNI). [Telex]17 maio 1982. Informa sobre a artista. Localizado no Arquivo Nacional em Brasília (DF). 
41 O embaixador Antônio Francisco de Azeredo da Silveira permaneceu no cargo de 1979 a 1983.

42 O professor Jorge Schwartz, filho da fotógrafa, encontrava-se em Washington na ocasião e confirma a informação. O contato telefônico foi realizado no dia 11 de julho de 2012 .

43 No arquivo do Baci, foi localizada apenas a inclusão do nome da fotógrafa na sugestão de programação enviada ao Itamaraty em 1981. Em carta ao Tenente Coronel Piero Ludovico Gobbato, Chefe da Assessoria Especial da Presidência da República, ela informa que a mostra ocorreria em setembro de 1982. Ver: Madalena Schwartz, [Carta] 26 abr. 1982, São Paulo, [para] Tenente Coronel Piero Ludovico Gobbato, Chefe da Assessoria Especial da Presidência da República. Localizada no Arquivo Nacional em Brasília (DF).

44 Jorge Schwartz, entrevista concedida por telefone a esta pesquisadora no dia 11 de julho de 2012, São Paulo.

45 No catálogo aparecem nomeados: Emanuel Araújo (na capa), Marco Nanini, Daniel Filho, Dercy Gonçalves, Irmã Dulce, Camafeu de Oxóssi (dono do Mercado Modelo, Salvador, BA), Henfil, Hermeto Pascoal, Carybé, Lygia Fagundes Telles, Ruth de Souza, Mário Cravo Jr., Mário Cravo Neto, Carlos Drummond de Andrade, Sérgio e Chico Buarque de Holanda, Maria José Carvalho, Irene Ravache, Pietro Maria Bardi, Jorge Amado, Jayme Lerner, d. Helder Câmara, Elza Soares e Bibi Ferreira. Ver Schwartz (1983).

46 Fernando Durão, “Aniversário da foto Cine Clube Bandeirante” (II), Folha da Tarde, Ilustrada, 18 de abril de 1983. Recorte de jornal localizado na biblioteca do Masp.

47 Pietro Maria Bardi, Como Acertar... Ver Schwartz (1983).

48 Foi exibida no Frick Arts Gallery, em Pittsburgh, em setembro de 1983; no The Photo Center Gallery na New York University Tisch School of Arts em dezembro de 1983; no Stanford Museum of Art em janeiro-fevereiro de 1984 e finalmente, no Martin Luther King, Jr. National Memorial Foundation Washington D.C. Ver Schwartz (1983). No entanto, apesar de não constar do catálogo, há a informação de que também foi exibida no Art Gallery da University of Florida em Gainesville, Florida. Ver Schwartz (1997).

49 Informações fornecidas à pesquisadora por Jorge Schwartz via e-mail datado de 6 de junho de 2012. Ainda em suas palavras, foi fundamental a intermediação do professor Frank Knight da Universidade de Johns Hopkins para que ela ocorresse.

50 Embaixada do Brasil, Washington (D.C.), EUA. [Carta-telegrama] 10 maio 1966, [de] Vasco Leitão Cunha, Secretaria de Estado das Relações Exteriores, Rio de Janeiro (RJ), Brasil. Informe sobre Exposição de Darcy Penteado, n.540.3(22). Localizada no Arquivo do Itamaraty em Brasília (DF).

51 José Neisten, entrevista concedida a esta pesquisadora em 30 de janeiro de 2012, Fairfax Village, Virgínia, EUA.

52 Marcel D. C. Hasslocher. Carta para Mr. Vance Kirkland. Director. University of Denver School of Art, Colorado. October 31, 1968. Washington. Localizado no Arquivo do Itamaraty em Brasília (DF).

53 Os funcionários do Baci eram contratados locais e apenas José Neistein tinha carteira de trabalho (José Neistein, entrevista concedida a esta pesquisadora por telefone em 9 de dezembro de 2015, São Paulo). 
54 José Neistein, Report of 1987. Washington (D.C.): Brazilian-American Cultural Institute, s.d., p.14. Localizado na Claire T. Carney Library, University of Massachussetts, Darmouth.

55 Ministério das Relações Exteriores, Brasília (DF), Brasil. [Correpondência] 6 mar. 1998, [de] Ext. [p/] Brasemb. Brasília (DF). Informa sobre liberação do valor de U\$29,175.00.

$56 \mathrm{O}$ endereço da nova sede era 4103 Connecticut Avenue, N. W. Por dezessete anos, o Baci esteve na 4201 Connecticut Avenue, N. W. Ver José Neistein, Report of 1985. Washington (D.C.): Brazilian-American Cultural Institute, s.d., p.13. Localizado na Claire T. Carney Library, University of Massachussetts, Darmouth. No entanto, no dia 16 de setembro de 1966, quando foi inaugurada, a sede localizava-se no Freudberg Building 4201 Connecticut Avenue, N.W. Na ocasião, Genaro Carvalho esteve expondo. Boletim Especial, n.166, 12 set. 1966.

57 José M. Neistein, Report of 1985. Washington (D.C.): Brazilian-American Cultural Institute, s.d., p.13. Localizado na Claire T. Carney Library, University of Massachussetts, Darmouth.

58 Ministério das Relações Exteriores, Brasília (DF), Brasil. [Correspondência] 20 dez. 2005, [da] SERE [p/] Brasemb.

59 Ministério da Justiça. Departamento de Polícia Federal. Centro de Informações. Informe n. 1492/01/V/83-CI/DPF, 24 de agosto de 1983. Localizado no Arquivo Nacional em Brasília (DF).

60 Ministério da Justiça. Departamento de Polícia Federal. Centro de Informações. Informe n. 1492/01/V/83-CI/DPF, 24 de agosto de 1983. Localizado no Arquivo Nacional em Brasília (DF).

61 Essa função foi mantida por José Neistein mesmo após o fechamento do Baci.

62 Ministério da Justiça. Departamento de Polícia Federal. Centro de Informações. Informe n. 1492/01/V/83-CI/DPF, 24 de agosto de 1983. Localizado no Arquivo Nacional em Brasília (DF).

\section{Referências}

ANGEL, F. The Latin American Presence. In: The Latin American Spirit: Art and Artists in the United States, 1920-1970. New York: The Bronx Museum of the Arts/ Harry N. Abrams, 1988. p. 238-239.

CAMNITZER, L.; WEISS, R. (Ed.) On Art, Artists, Latin America, and Other Utopias. Austin, TX, USA: University of Texas Press, 2009. p.172. ["while members of the committee distributed literature to the visitors, members of MICLA gave out "contra ex-votos' bandaged fragments of dolls."]

GARCIA, C. M. Importância e formas de aprimoramento da atividade de difusão cultural como instrumento da politica externa brasileira. Brasília, 2003. Tese (Doutorado em Política Externa Brasileira) - Curso de Altos Estudos, Instituto Rio Branco.

LEIRNER, N. The Rebellion of the Animals: a series of drawings. Art Gallery of the Brazilian-American Cultural Institute Washington (D. C.), march/april 1974. 
MARIZ, V. Introdução. In: Quem é quem nas artes e nas letras do Brasil. Rio de Janeiro: Ministério das Relações Exteriores, 1966.

MELLO BARRETO, F. de. A política externa durante o regime militar. Politica Externa, v.22, n.4, p.8-9, abr./mai./jun. 2014.

MOTTA, F. O desenho voltou. In: LEIRNER, N. The Rebellion of the Animals: a series of drawings. Art Gallery of the Brazilian-American Cultural Institute Washington (D. C.), march/april 1974.

RIBEIRO, E. T. Diplomacia cultural. Seu papel na política externa brasileira. Brasília (DF): Fundação Alexandre Gusmão, 2011.

SCHWARTZ, M. Personae: fotos e faces do Brasil. São Paulo: Cia. das Letras, 1997.

. O Rosto Brasileiro/ The Brazilian face. São Paulo: Museu de Arte de São Paulo Assis Chateaubriand, 19 de abril a 8 de maio de 1983.

RESUMO - Acompanhar a história do Brazilian American Cultural Institute (Baci) possibilita conhecer aspectos da diplomacia cultural brasileira nos Estados Unidos durante o período da guerra fria. A hipótese aqui apresentada é a de que os espaços de arte e de cultura funcionaram como importantes ambientes de articulação social nas atividades diplomáticas e comerciais, sendo o Baci um caso bastante revelador desse processo. No entanto, essa realidade se altera no mundo contemporâneo globalizado, pois os espaços artísticos e culturais parecem ter deixado de ser vitais para a prática da diplomacia cultural, como o fechamento do Baci revela.

PALAVRAS-CHAVE: Brazilian American Cultural Institute, Baci, Diplomacia cultural brasileira nos Estados Unidos, Arte brasileira nos Estados Unidos, José Menache Neistein.

ABSTRACT - The history of the Brazilian American Cultural Institute (Baci) enables us to learn about aspects of Brazilian cultural diplomacy in the United States during the Cold War period. The hypothesis presented here is that the spaces of art and culture functioned as important social engagement environments for diplomatic and commercial activities, with Baci being a very revealing case of this process. However, this reality changed in the contemporary globalized world, as artistic and cultural spaces seem to have ceased to be vital for the practice of cultural diplomacy, as the closing of Baci reveals.

KEYWORDS: Brazilian American Cultural Institute, Baci, Brazilian cultural diplomacy in the United States, Brazilian art in the United States, José Menache Neistein.

Dária Jaremtchuk é professora livre-docente pela Escola de Artes, Ciências e Humanidades da Universidade de São Paulo (EACH-USP), onde também é professora de História das Artes nos cursos de graduação, e vinculada aos Programas e Pós-graduação em Artes Visuais da Escola de Comunicações e Artes da USP e Estudos Culturais da EACH-USP. @-dariaj@usp.br / https://orcid.org/0000-0002-8161-9045.

Recebido em 20.4.2020 e aceito em 9.11.2020.

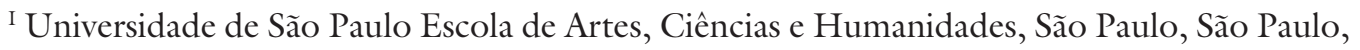
Brasil. 
